AIRWAY BIOLOGY

\title{
Airway function and markers of airway inflammation in patients with treated hypothyroidism
}

\author{
S S Birring, R B Patel, D Parker, S Mckenna, B Hargadon, W R Monteiro, J F Falconer Smith, \\ I D Pavord
}

See end of article for authors' affiliations

.....................

Correspondence to: Dr S S Birring, Institute for Lung Health, Department of Respiratory Medicine, Glenfield Hospital, Leicester LE3 9QP, UK; sb134@le.ac.uk

Received

15 September 2004

Accepted

26 November 2004
Background: There is increasing evidence of an association between organ specific autoimmune diseases, particularly autoimmune thyroid disease and respiratory morbidity. A study was undertaken to determine whether patients with autoimmune thyroid disease have objective evidence of airway inflammation and dysfunction.

Methods: Twenty six non-smoking women with treated hypothyroidism and 19 non-smoking controls completed a symptom questionnaire and underwent full lung function tests, capsaicin cough reflex sensitivity measurement, methacholine challenge test, and sputum induction over two visits.

Results: Symptoms of cough $(p=0.01)$, dyspnoea $(p=0.01)$, sputum production $(p=0.004)$, and wheeze $(p=0.04)$ were reported more commonly in patients than controls. Patients with hypothyroidism had heightened cough reflex sensitivity compared with controls (geometric mean concentration of capsaicin causing five coughs: 40 v $108 \mathrm{mmol} / \mathrm{l}$; mean difference 1.4 doubling doses; $95 \%$ confidence interval of difference 0.4 to $2.5 ; p=0.008$ ) and a significantly higher proportion of patients had airway hyperresponsiveness (methacholine provocative concentration $\left.\left(\mathrm{PC}_{20}\right)<8 \mathrm{mg} / \mathrm{ml}: 38 \% v 0 \% ; \mathrm{p}=0.016\right)$. Patients with hypothyroidism also had a significantly higher induced sputum total neutrophil cell count $(p=0.01)$, total lymphocyte count $(p=0.02)$, and sputum supernatant interleukin-8 concentrations $(\mathrm{p}=0.048)$.

Conclusion: Patients with treated hypothyroidism report more respiratory symptoms and have objective evidence of airway dysfunction and inflammation.
W e have previously shown that subjects with unexplained $\operatorname{cough}^{1-3}$ and non-smoking subjects with fixed airflow obstruction ${ }^{4}$ have a high prevalence of organ-specific autoimmune disease and a high prevalence of organ specific autoantibodies. The association with autoimmune hypothyroidism is particularly striking. Subjects with treated hypothyroidism report common respiratory symptoms more often than healthy controls. ${ }^{5}$ Furthermore, the profile of respiratory symptoms is similar to that seen in inflammatory bowel disease. ${ }^{5}$ We have suggested that the increased respiratory symptoms are due to airway inflammation as a result of aberrant homing of inflammatory cells to the lungs from the primary site of chronic inflammation. ${ }^{1} 24$

We set out to test the hypothesis that non-smoking patients with hypothyroidism have objective evidence of airway dysfunction and airway inflammation in a controlled cross sectional observational study.

\section{METHODS}

\section{Subjects}

Twenty six patients with treated hypothyroidism were randomly chosen from the Leicestershire Thyroid Register. This is a register of Leicestershire patients diagnosed with primary hypothyroidism from primary $(48 \%)$ and secondary care $(52 \%)$. All patients at the time of diagnosis had raised thyroid stimulating hormone levels with suppressed thyroxine levels not due to treatment or surgery. At the time of entry into the study, all patients were on appropriate thyroid replacement therapy and were biochemically euthyroid. Age and sex matched normal controls were recruited from healthy volunteers responding to local advertising. Patients with hypothyroidism and controls were excluded if they were current smokers or had a past smoking history of $>10$ pack years, had stopped smoking less than l year before study entry, had an upper respiratory tract infection in the past 8 weeks, or had at any point in the past received a diagnosis of respiratory disease, upper airway disorders, or gastrooesophageal reflux or who had significant co-morbidities. Patients taking $\beta$ blockers and angiotensin converting enzyme inhibitors were also excluded because of their potential effect on airway function. Subjects were asked for their consent to participate and the protocol was approved by the Leicestershire ethics committee.

\section{Protocol and clinical measurement}

The subjects attended on two occasions. At the first visit all subjects completed a questionnaire enquiring about the presence of respiratory symptoms (cough, breathlessness, sputum and wheeze $)^{56}$ and had skin prick tests for common aeroallergens (Dermatophagoides pteronyssinus, cat fur, dog dander, and grass pollen). Atopy was defined as the presence of a weal $>2 \mathrm{~mm}$ larger than the negative control. All subjects had blood taken for measurement of thyroid peroxidase autoantibodies (fluorescent ELISA system, Pharmacia Diagnostics, Milton Keynes, UK), serum angiotensin converting enzyme (ACE) level, and $\alpha_{1}$-antitrypsin level, and a capsaicin cough reflex sensitivity measurement was made using a dosimeter method standardised to limit inspiratory flow to $0.5 \mathrm{l} / \mathrm{s}^{78}$

At the second visit subjects had a chest radiograph and pulmonary function tests. Spirometric tests were performed with a Vitalograph spirometer (Vitalograph, Buckinghamshire, UK) before and 15 minutes after salbutamol $2.5 \mathrm{mg}$ administered via a Flaem Nouva Type II nebuliser (Deva Medical, Runcorn, Cheshire, UK; median particle size $2 \mu \mathrm{m})$. Forced expiratory volume in 1 second $\left(\mathrm{FEV}_{1}\right)$ was 
recorded as the best of three successive readings within $100 \mathrm{ml}$. Lung function tests were done with a benchmark (P K Morgan, Chatham, UK) and lung volumes assessed by the helium dilution method. Exhaled nitric oxide, methacholine hyperresponsiveness, and sputum induction were measured using methods that have been described previously. ${ }^{9-11}$ Briefly, for sputum induction, sputum was induced with $3 \%$, $4 \%$ and $5 \%$ saline inhaled in sequence for 5 minutes via an ultrasonic nebuliser (Medix, Harlow, UK). After each inhalation patients expectorated into a sterile pot. Sputum free of salivary contamination was selected and was mixed with four times its volume of $0.1 \%$ dithiothreitol. From the induced sputum sample, a differential cell count was obtained from a cytospin preparation stained with Romanowski's stain, and a total cell count was determined using a haemocytometer. The sputum supernatant was stored at $-80^{\circ} \mathrm{C}$ until mediator analysis $(<6$ months). Cell counting was performed by an experienced observer blind to the subject's clinical characteristics.

\section{Mediator measurements}

The concentrations of mediators in sputum supernatant were determined within 6 months of obtaining samples by competitive enzyme immunoassays for histamine (Immunotech, Marseille, France), sandwich enzyme linked immunosorbent assay for interleukin (IL)-8 (Pharmingen, San Diego), and the concentrations obtained were the mean of duplicate samples. The sensitivity of the assays were $50 \times 10^{-3} \mathrm{ng} / \mathrm{ml}$ for histamine and $0.8 \times 10^{-3} \mathrm{ng} / \mathrm{ml}$ for IL- 8 . The intra-assay coefficient of variability of the assays was $5-10 \%$ and the interassay coefficient of variability was 3-15\% across the range of concentrations of mediators measured. Spiking experiments have shown $>90 \%$ recovery across the range of concentrations encountered. ${ }^{9}{ }^{12}$

Table 1 Subject characteristics and pulmonary function tests

\begin{tabular}{lll}
\hline & Normal & Hypothyroid \\
\hline $\mathrm{N}$ (male) & $19(0)$ & $26(0)$ \\
Age (years) & $48(3)$ & $52(3)$ \\
Body mass index $\left(\mathrm{kg} / \mathrm{m}^{2}\right.$ ) & $24.0(0.4)$ & $28.8(1.0)^{* *}$ \\
Ex-smokers (n) & 6 & 4 \\
Pack year smoking in & 2 & 3 \\
ex-smokers & & \\
Serum T4 (NR 10-25 pmol/l) & $14.1(0.4)$ & $16.7(0.5)^{* *}$ \\
TSH (NR 0.3-5.0 mU/) & $2.2(0.5)$ & $1.9(0.5)$ \\
Duration of hypothyroidism (years) & - & $11(2)$ \\
Positive thyroid autoantibodies, & $1(5)$ & $25(96)^{* *}$ \\
$\mathrm{n}(\%)$ & $4(21)$ & $5(19)$ \\
Atopy, n (\%) & $3(16)$ & $12(46)^{*}$ \\
Cough, $\mathrm{n}(\%)$ & $2(11)$ & $12(46)^{*}$ \\
Breathlessness, n (\%) & 0 & $9(35)^{* *}$ \\
Sputum, n (\%) & 0 & $5(19)^{*}$ \\
Wheeze, n (\%) & $110(3)$ & $110(4)$ \\
FEV $(\%$ predicted) & $83(1)$ & $81(2)$ \\
FEV $/$ FVC (\%) & $83(3)$ & $85(4)$ \\
RV (\% predicted) & $98(2)$ & $102(2)$ \\
TLC (\% predicted) & $99(3)$ & $98(3)$ \\
TLCO (\% predicted) & $104(2)$ & $103(2)$ \\
Kco (\% predicted) & 0 & $38^{*}$ \\
PC 20 FEV $<8$ mg/ml & & \\
(\% of subjects) & &
\end{tabular}

Data expressed as mean (SE).

Positive thyroid autoantibody, thyroid peroxidase titre $>1: 60 ; n$, number; $\mathrm{NR}$, normal range; TSH, thyroid stimulating hormone; $\mathrm{FEV}_{1}$, forced expiratory volume in 1 second; FVC, forced vital capacity; RV, residual volume; TLC, total lung capacity; TLCO, carbon monoxide transfer factor; $\mathrm{KCO}$, carbon monoxide transfer coefficient; $\mathrm{PC}_{20}$, provocative concentration of methacholine.

${ }^{*} p<0.05 ;{ }^{* *} p<0.001$ ( $\chi^{2}$ test).

\section{Analysis of data}

Subject characteristics were described using descriptive statistics and expressed as mean (SE) values. The criteria for the presence of symptoms were as previously described. ${ }^{5}$ The concentration of methacholine needed to provoke a fall in $\mathrm{FEV}_{1}$ of $20 \%$ or more $\left(\mathrm{PC}_{20}\right) \mathrm{FEV}_{1}$ and concentration of capsaicin causing two and five coughs (C2 and C5 in $\mu \mathrm{mol} / \mathrm{l}$ ) were calculated by linear interpolation of the log doseresponse curves and described as geometric mean (log SE). Comparisons of mediator concentrations, sputum differential cell counts, and exhaled nitric oxide concentrations were undertaken using the Mann-Whitney $\mathrm{U}$ test and unpaired $t$ tests for non-parametric data and parametric data, respectively. $\chi^{2}$ tests were used for comparisons between groups in the prevalence of airway hyperresponsiveness $\left(\mathrm{PC}_{20}<8 \mathrm{mg} /\right.$ $\mathrm{ml}$ ) and airway symptoms. A value of $\mathrm{p}<0.05$ was considered statistically significant. The analyses were repeated using analysis of covariance with serum $\mathrm{T} 4$ and body mass index (BMI) as independent variables. The study was powered to show a difference of more than 1.5 doubling doses in cough reflex sensitivity.

\section{RESULTS}

There were significant differences in BMI $\left(24.0 v 28.8 \mathrm{~kg} / \mathrm{m}^{2}\right.$; mean difference $4.8 ; 95 \%$ confidence interval (CI) of difference 2.5 to $7.1 ; \mathrm{p}<0.001)$ and serum $\mathrm{T} 4$ (14.1 $v$ $16.7 \mathrm{pmol} / \mathrm{l} ; 95 \% \mathrm{CI}$ of difference 1.3 to $3.8 ; \mathrm{p}<0.001$ ) between controls and patients with hypothyroidism, but otherwise the groups were well matched. The subject
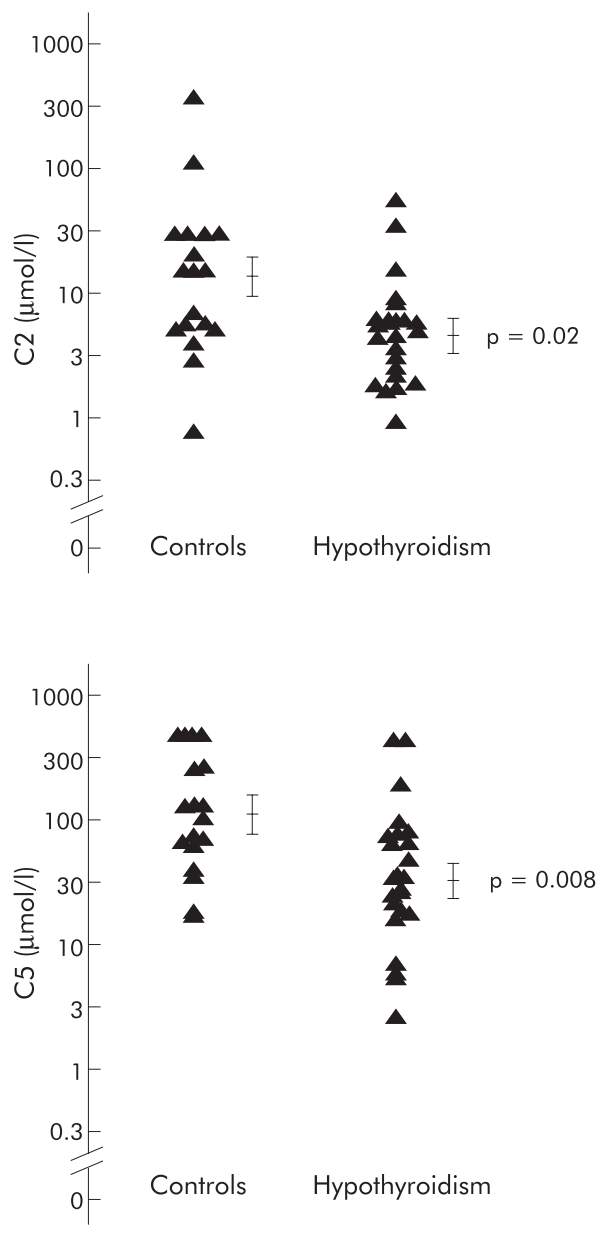

Figure 1 Capsaicin cough reflex sensitivity. Data expressed as mean ( $\log$ SE). C2, C5, concentrations of capsaicin causing two and five coughs, respectively $(\mu \mathrm{mol} / \mathrm{l})$. 
characteristics are shown in table 1 . All subjects had normal chest radiographs, serum ACE and $\alpha_{1}$-antitrypsin levels. Patients with hypothyroidism had a significantly higher prevalence of respiratory symptoms than controls (cough $(\mathrm{p}=0.01)$, breathlessness $(\mathrm{p}=0.01)$, sputum $(\mathrm{p}=0.004)$ and wheeze $(p=0.04)$; table 1$)$. Three patients with hypothyroidism ( $12 \%)$ but no controls had evidence of fixed airflow obstruction (post-bronchodilator $\mathrm{FEV}_{\mathrm{l}} / \mathrm{FVC}$ : 49\%, 64\% and 68\%; methacholine $\mathrm{PC}_{20} \mathrm{FEV}_{1} 1.5 \mathrm{mg} / \mathrm{ml},>16 \mathrm{mg} / \mathrm{ml}$ and $3.5 \mathrm{mg} / \mathrm{ml}$; sputum differential eosinophil count (our normal range $<1.9 \%$ ): not obtained, $14 \%$ and $1.7 \%$; exhaled nitric oxide levels (our normal range $<10 \mathrm{ppb}$ ) 3.7, 17.3 and $10 \mathrm{ppb}$ respectively). There were no other significant differences in spirometric and lung function tests between the two groups (table 1). Patients with hypothyroidism had a significantly higher prevalence of airway hyperresponsiveness to methacholine $\left(\mathrm{PC}_{20} \mathrm{FEV}_{1}<8 \mathrm{mg} / \mathrm{ml}\right)$ than controls $(38 \% \vee 0 \%$; $\mathrm{p}=0.02$; table 1 ) and a significantly more sensitive cough reflex than controls for both geometric mean C2 (5.6 v $14.2 \mathrm{mmol} / \mathrm{l}$; mean difference 1.3 doubling doses; $95 \%$ CI of difference 0.2 to $2.4 ; \mathrm{p}=0.02)$ and C5 (107.9 $\vee 40 \mathrm{mmol} / \mathrm{l}$; mean difference 1.4 doubling doses; $95 \%$ CI of difference 0.4 to $2.5 ; \mathrm{p}=0.008$; fig 1 ).

Adequate sputum samples were obtained from 18 patients with hypothyroidism and 13 controls, of whom 13 and 6 , respectively, had sufficient sputum supernatants available to perform mediator assays. The sputum absolute cell counts and supernatant mediator concentrations were as shown in table 2 and figs 2 and 3 . The median sputum absolute neutrophil and lymphocyte cell counts $\left(\times 10^{4}\right.$ cells/g sputum) were significantly higher in patients with hypothyroidism than controls (neutrophils: $117.5 \vee 54.7$; median difference 62.8; $95 \%$ CI of difference 12.3 to $166 ; \mathrm{p}=0.01$ (fig 3); lymphocytes: $1.5 \vee 0.1$; median difference $1.4 ; 95 \%$ CI of difference 0.1 to $3.3 ; \mathrm{p}=0.02$ ). Sputum total cell counts were significantly higher in patients with hypothyroidism than in controls, but there were no other differences in sputum leucocyte absolute or differential cell counts between groups (table 2). Median sputum supernatant IL-8 concentrations were significantly higher in patients with hypothyroidism $(11 \mathrm{ng} / \mathrm{ml})$ than in controls $(3.3 \mathrm{ng} / \mathrm{ml}$; median difference $7.7 \mathrm{ng} / \mathrm{ml} ; 95 \% \mathrm{CI}$ of difference 0.1 to $19.9 ; \mathrm{p}<0.05$; table 2 , fig 3).

\begin{tabular}{|c|c|c|}
\hline & Normal & Hypothyroid \\
\hline Exhaled nitric oxide (ppb) $\dagger$ & $1.4(0.2)$ & $3.2(0.1)$ \\
\hline Interleukin-8 (ng/ml) & $3.3(2.2-9.7)$ & $11(4.9-28.5)^{*}$ \\
\hline Histamine $(\mathrm{ng} / \mathrm{ml})$ & $10.8(2.1-36.0)$ & $3.8(1.7-33.1)$ \\
\hline \multicolumn{3}{|l|}{ Absolute cell counts $\left(\times 10^{4} / \mathrm{g}\right)$} \\
\hline Neutrophils & $54.7(10.4-122.2)$ & $117.5(65.3-275.6)^{*}$ \\
\hline Eosinophils & $0.0(0-0.6)$ & $1.5(0-4.5)$ \\
\hline Lymphocytes & $0.1(0-1.3)$ & $1.5(0-4.5)^{\star}$ \\
\hline Macrophages & $10.0(2.2-93.4)$ & $36.4(11.4-93.4)$ \\
\hline Epithelial cells & $0.5(0-4.5)$ & $2.9(0.8-8.3)$ \\
\hline Total cell count $\left(\times 10^{6} / \mathrm{ml}\right)$ & $0.5(0.2-2.0)$ & $2.1(1.1-3.3)^{*}$ \\
\hline \multicolumn{3}{|l|}{ Differential cell counts (\%) } \\
\hline Neutrophils & $64.0(52.9-85.2)$ & $69.4(59.7-88.2)$ \\
\hline Eosinophils & $0.3(0-0.4)$ & $0.5(0.1-1.7)$ \\
\hline Lymphocytes & $0.6(0-0.8)$ & $1.0(0.2-1.5)$ \\
\hline Macrophages & $34.8(13.0-44.9)$ & $22.7(6.6-31.8)$ \\
\hline Epithelial cells & $1.0(0.1-2.7)$ & $1.6(0.4-3.8)$ \\
\hline Viability (\%)‡ & $46(6)$ & $68(4)$ \\
\hline $\begin{array}{l}\text { Squamous cell contamination } \\
(\%) \ddagger\end{array}$ & $14(4)$ & $10(6)$ \\
\hline
\end{tabular}

Data expressed as median (25-75th percentile) except where indicated: tgeometric mean (log SE); †mean (SE); absolute cell counts $\times 10^{4} / \mathrm{g}$ sputum. ${ }^{*} \mathrm{p}<0.05$ (Mann-Whitney test).

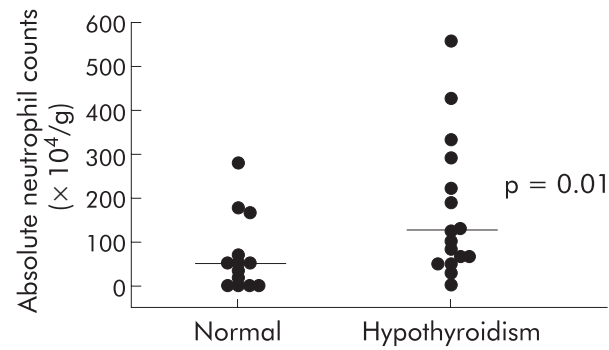

Figure 2 Median induced sputum absolute neutrophil cell counts $\left(\times 10^{4}\right.$ cells/g sputum).

With the exception of wheeze, which was significantly more common in those with BMI $>30 \mathrm{~kg} / \mathrm{m}^{2}$, there was no correlation between BMI, serum $\mathrm{T} 4$, and any outcome measures. Differences between hypothyroid and controls were unaffected when BMI and serum T4 were analysed as additional independent factors using analysis of covariance.

\section{DISCUSSION}

This is the first study to investigate airway function and inflammation in subjects with hypothyroidism. We found that patients with treated hypothyroidism had an increased cough reflex sensitivity and were more likely to have increased airway hyperresponsiveness. There was also evidence of airway inflammation as reflected by an increased inflammatory cell count, absolute neutrophil count, absolute lymphocyte count, and sputum IL-8 concentration. Our findings support the hypothesis that there is airway dysfunction and inflammation in patients with hypothyroidism.

This is a descriptive study of an area that has not been investigated before. Our subjects performed multiple tests and we have measured multiple outcomes so there is the potential that the differences we have observed occurred by chance. There were also differences in baseline BMI and serum T4 levels. It is therefore important to regard our results as hypothesis generating and not definitive. Further studies with more focused outcome measures are required to test our hypothesis more fully. Nevertheless, the changes we have observed are consistent in direction; they were not influenced when analysis allowed for baseline differences in BMI and serum T4, and some of the differences seen between normal subjects and patients with hypothyroidism were highly significant. The effects we have seen are also consistent with previous work linking hypothyroidism to idiopathic chronic cough $^{1}$ and chronic obstructive pulmonary disease (COPD) in non-smokers. ${ }^{4}$ These factors make it likely that the differences seen are real.

Hypothyroid subjects reported common respiratory symptoms more often than controls. This supports our recent

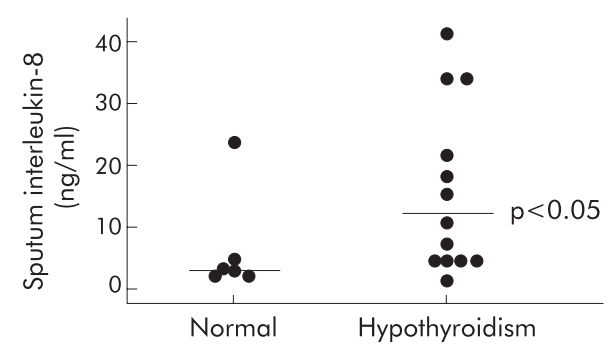

Figure 3 Median sputum supernatant interleukin-8 concentrations (ng/ml). 
prospective study of 124 patients with treated hypothyroidism and 1346 healthy controls where we found a 2-3-fold increase in the prevalence of cough, breathlessness, and sputum production in patients with treated hypothyroidism. ${ }^{5}$ Apart from a small excess of wheeze in this current study, the prevalence and profile of symptoms in our small population was similar to that seen in the larger study which suggests that we studied a representative sample and our findings can be generalised to a larger population of patients with hypothyroidism. It is important to emphasise that we only studied women, partly because they account for the vast majority of patients with hypothyroidism. We doubt that our findings are confined to women although further work is required to confirm this.

The most striking finding in our study was increased cough reflex sensitivity. There was also evidence of airway inflammation with an increased total inflammatory cell count, total neutrophil count, total lymphocyte count, and sputum IL-8 concentration. We found fixed obstructive spirometric defects in three hypothyroid subjects. Apart from increased airway responsiveness (which is a non-specific finding in patients with abnormal spirometry), ${ }^{13}$ the spirometric defects were not associated with typical features of asthma in two of the three subjects. Fixed upper airway obstruction is unlikely as none of our patients had clinical evidence of a goitre and inspiratory flows were normal. Fixed airflow obstruction is an unusual finding in the general population. Our findings may therefore be consistent with an association between hypothyroidism and COPD in nonsmokers, ${ }^{4}$ although larger controlled studies are required to investigate the possibility more definitively.

Airway inflammation was assessed using a wide variety of cellular and molecular markers in induced sputum. We chose to compare total as well as differential cell counts in order to assess the intensity as well as the characteristics of the inflammatory response and because the relationship between neutrophilic airway inflammation and differential neutrophil counts is non-linear in the range of differential cell counts observed in this study. ${ }^{14}$ These results need to be interpreted allowing for the fact that sputum induction was only successful in $68 \%$ of controls and $69 \%$ of patients with hypothyroidism and that adequate sputum supernatant for mediator measurements was not available in all of them. If anything, the low success rate should have minimised our chances of showing a significant difference and there is no a priori reason to suggest a bias in the other direction.

We found modest increases in the total inflammatory cell count, number of neutrophils and lymphocytes and sputum IL-8 concentration. Similar abnormalities have been observed in a diverse range of condition including COPD, ${ }^{45}$ cryptogenic fibrosing alveolitis, ${ }^{16}$ and non-asthmatic chronic cough. ${ }^{17}$ This suggests that our findings should be regarded as a non-specific indication of airway inflammation rather than indicative of a specific disease process. Nevertheless, the cell and mediator profile seen in our population is similar to that seen in patients with idiopathic chronic cough ${ }^{17}$ and in non-smokers with COPD, ${ }^{4}$ supporting the view that there is an association between hypothyroidism and these conditions.

Previous bronchoscopic studies have found evidence of lymphocytic inflammation in patients with idiopathic chronic cough, many of whom have evidence of organ-specific autoimmune disease. ${ }^{218}$ Bronchoalveolar lymphocytosis is also seen in sarcoidosis, ${ }^{19}$ extrinsic allergic alveolitis, ${ }^{20}$ inflammatory bowel disease, ${ }^{21}$ post-transplant chronic lung rejection, ${ }^{22}$ and pulmonary involvement in rheumatoid arthritis $^{23}$ and Sjogren's disease. ${ }^{24}$ We found a significantly increased sputum lymphocyte count in patients with hypothyroidism consistent with the presence of lymphocytic airway inflammation. However, induced sputum is not an ideal technique to investigate lymphocytic airway inflammation since lymphocyte numbers are low. ${ }^{25}$ Further studies using bronchial biopsy and bronchoalveolar lavage are required to confirm this finding and to determine the phenotypic characteristics of lymphocytes involved.

What is the mechanism of the airway dysfunction and inflammation seen in this study? We have studied nonsmokers and there were no difference in markers of atopy, $\alpha_{1}$-antitrypsin levels, or serum ACE concentrations, so our findings cannot be due to differences in these markers of inflammatory lung disease. Similarly, our findings are unlikely to be due to thyroid hormone status since all subjects were biochemically euthyroid at the time of testing. Cardiac disease is common in patients with autoimmune thyroid disease but unlikely to be responsible for respiratory symptoms, given the absence of signs of cardiac disease on the chest radiograph and the presence of relatively specific indicators of airway disease such as increased cough sensitivity, increased airway hyperresponsiveness, and increased sputum cells and inflammatory mediators. Hypothyroidism is usually due to an autoimmune process and is characterised by an intense lymphocytic inflammatory process within the thyroid. $96 \%$ of our subjects with hypothyroidism had positive thyroid peroxidase autoantibodies, in keeping with an autoimmune basis to their hypothyroidism. The airways and the thyroid have common embryological origins and it is plausible that the associated lung inflammation and dysfunction is due to the spread of the chronic inflammatory process from the thyroid to the lungs secondary to abhorrent homing. A similar mechanism is thought to underlie the airways dysfunction and inflammation seen in subjects with inflammatory bowel disease. ${ }^{5}$ If this mechanism is important, then there is clear potential for other conditions associated with chronic inflammation of structures embryologically linked to the lungs to be associated with airway dysfunction and inflammation. Although the link between airway disease and chronic inflammatory conditions such as autoimmune hypothyroidism is most clearly recognised in patients with unusual features (for example, idiopathic chronic cough, COPD in non-smokers), future studies should investigate the possibility that the airway complications of these conditions are relevant to a larger group of patients with cough and COPD.

\section{ACKNOWLEDGEMENTS}

The authors thank the subjects who participated in the study; Natalie Neale, Shelly Kirk, Dhiraj D Vara and the Department of Respiratory Physiology for assistance in the clinical characterisation of some of the patients; and Neville Pierse (Statistician, Institute of Environmental Health, University of Leicester) for help in analysing the data.

\section{Authors' affiliations \\ S S Birring, R B Patel, D Parker, S Mckenna, B Hargadon, W R Monteiro, J F Falconer Smith, I D Pavord, Institute for Lung Health, Department of} Respiratory Medicine, Glenfield Hospital, Leicester, UK

This study was funded by The British Lung Foundation and University Hospitals of Leicester NHS Trust. Surinder Birring is a British Lung Foundation Clinical Research Fellow.

Conflicts of interest: None declared

\section{REFERENCES}

1 Birring SS, Murphy AC, Scullion JE, et al. Idiopathic chronic cough and organspecific autoimmune diseases: a case-control study. Respir Med 2004;98:242-6.

2 Birring SS, Brightling CE, Symon FA, et al. Idiopathic chronic cough: association with organ specific autoimmune disease and bronchoalveola lymphocytosis. Thorax 2003;58:1066-70.

3 Birring SS, Parker D, Brightling CE, et al. Induced sputum mediator concentrations in chronic cough. Am J Respir Crit Care Med 2003;169:15-9. 
4 Birring SS, Brightling CE, Bradding $P$, et al. Clinical, radiologic, and induced sputum features of chronic obstructive pulmonary disease in nonsmokers: a descriptive study. Am J Respir Crit Care Med 2002;166:1078-83.

5 Birring SS, Morgan AJ, Prudon B, et al. Respiratory symptoms in patients with treated hypothyroidism and inflammatory bowel disease. Thorax 2003:58:533-6.

6 Burney PG, Laitinen LA, Perdrizet S, et al. Validity and repeatability of the IUATLD (1984) Bronchial Symptoms Questionnaire: an international comparison. Eur Respir J 1989;2:940-5.

7 Brightling CE, Ward R, Wardlaw AJ, et al. Airway inflammation, airway responsiveness and cough before and after inhaled budesonide in patients with eosinophilic bronchitis. Eur Respir J 2000;15:682-6.

8 Dicpinigaitis PV, Rauf K. The influence of gender on cough reflex sensitivity. Chest 1998;113:1319-21.

9 Brightling CE, Ward R, Woltmann G, et al. Induced sputum inflammatory mediator concentrations in eosinophilic bronchitis and asthma. Am J Respir Crit Care Med 2000; 162:878-82.

10 Green RH, Brightling CE, McKenna S, et al. Asthma exacerbations and sputum eosinophil counts: a randomised controlled trial. Lancet 2002;360:1715-21.

11 Pizzichini E, Pizzichini MM, Efthimiadis A, et al. Indices of airway inflammation in induced sputum: reproducibility and validity of cell and fluidphase measurements. Am J Respir Crit Care Med 1996;154:308-17.

12 Birring SS, Parker D, Brightling CE, et al. Induced sputum inflammatory mediator concentrations in chronic cough. Am J Respir Crit Care Med 2004; 169:15-9.

13 Juniper EF, Cockcroft DW, Hargreave FE. Histamine and methacholine inhalation tests: a laboratory tidal breathing protocol. Lund, Sweden: Astra Daco DB, 1994.

14 Neale N, Parker D, Barlow S, et al. The relationship between total and differential cell counts in induced sputum. Eur Respir J 2002;20:274s.
15 Beeh KM, Kornmann O, Buhl R, et al. Neutrophil chemotactic activity of sputum from patients with COPD: role of interleukin 8 and leukotriene B4. Chest 2003; 123:1240-7.

16 Beeh KM, Beier J, Kornmann O, et al. Neutrophilic inflammation in induced sputum of patients with idiopathic pulmonary fibrosis. Sarcoidosis Vasc Diffuse Lung Dis 2003;20:138-43.

17 Jatakanon A, Lalloo UG, Lim S, et al. Increased neutrophils and cytokines, TNF-alpha and IL-8, in induced sputum of non-asthmatic patients with chronic dry cough. Thorax 1999;54:234-7.

18 Brightling CE, Symon FA, Birring SS, et al. A case of cough, lymphocytic bronchoalveolitis and coeliac disease with improvement following a gluten free diet. Thorax 2002:57:91-2.

19 Inui N, Chida K, Suda T, et al. TH1/TH2 and TC1/TC2 profiles in peripheral blood and bronchoalveolar lavage fluid cells in pulmonary sarcoidosis. $J$ Allergy Clin Immunol 2001;107:337-44.

20 Wahlstrom J, Berlin M, Lundgren R, et al. Lung and blood T-cell receptor repertoire in extrinsic allergic alveolitis. Eur Respir J 1997;10:772-9.

21 Bonniere $\mathbf{P}$, Wallaert $B$, Cortot $A$, et al. Latent pulmonary involvement in Crohn's disease: biological, functional, bronchoalveolar lavage and scintigraphic studies. Gut 1986;27:919-25.

22 Yousem SA. Lymphocytic bronchitis/bronchiolitis in lung allograft recipients. Am J Surg Pathol 1993;17:491-6.

23 Gabbay E, Tarala R, Will R, et al. Interstitial lung disease in recent onset rheumatoid arthritis. Am J Respir Crit Care Med 1997;156:528-35.

24 Wallaert B, Prin L, Hatron PY, et al. Lymphocyte subpopulations in bronchoalveolar lavage in Sjogren's syndrome. Evidence for an expansion of cytotoxic/suppressor subset in patients with alveolar neutrophilia. Chest 1987:92:1025-31.

25 Pavord ID, Pizzichini MM, Pizzichini E, et al. The use of induced sputum to investigate airway inflammation. Thorax 1997;52:498-501.

\section{LUNG ALERT}

\section{Nortriptyline may help in smoking cessation}

$\Delta$ Prochazka AV, Kick S, Steinbrunn C, et al. A randomized trial of nortriptyline combined with transdermal nicotine for smoking cessation. Arch Intern Med 2004;164:2229-33

T his double blind, randomised, controlled trial compared smoking cessation rates of nortriptyline with placebo in addition to transdermal nicotine and a behavioural smoking cessation programme. 158 subjects aged 18-65 years were enrolled, all of whom smoked 10 or more cigarettes daily. Nortriptyline $(25 \mathrm{mg} /$ day, titrated up to $75 \mathrm{mg} /$ day as tolerated) or matched placebo commenced 14 days before the "quit date" and continued for 12 weeks thereafter. Withdrawal symptoms were monitored. The primary outcome measure-sustained smoking abstinence at 6 months (self-reported cessation, expired $\mathrm{CO}_{2}$ concentration $(<9 \mathrm{ppm})$, and urine cotinine level $\left.<50 \mathrm{ng} / \mathrm{ml}\right)$-was assessed with statistical analyses performed and adjustment made for numerous covariates. The nortriptyline group had a sustained abstinence rate of $23 \%$ compared with $10 \%$ in the placebo arm (95\% CI 1.3 to 24.5$) ; p=0.052$, odds ratio (OR) 2.62 (95\% CI 1.06 to 6.44 ). This effect was weakened after adjustment for cigarettes previously smoked per day (OR 2.31 (95\% CI 0.92 to 5.76), $\mathrm{p}=0.07$ ). Withdrawal symptoms were similar in each group, suggesting that nortriptyline has little beneficial effect over transdermal nicotine alone. Adverse effects were significantly higher in those on nortriptyline-indeed, the authors postulate that the induced dry mouth and dysgeusia may decrease upper airway sensory stimulation and hence enhance cessation success.

The power of this study is limited as only a small number of subjects quit. Success rates of $23 \%$ at 6 months are associated with a significant adverse effect profile as well as prerequisite screening requirements (ECG). However, improvement on current cessation therapy rates is made. In a supervised programme, nortriptyline may have a role in this important public health issue. 